\title{
Education in the Network Society: Challenges and Prospects
}

\author{
Daria Dobrinskaya \\ Lomonosov Moscow State University \\ Moscow, Russia \\ E-mail: darya.dobrinskaya@gmail.com
}

\author{
Artemiy Kurbanov \\ Lomonosov Moscow State University \\ Moscow, Russia \\ E-mail: ark112@yandex.ru
}

\author{
Inna Vershinina \\ Lomonosov Moscow State University \\ Moscow, Russia \\ E-mail: urbansociology@yandex.ru
}

\begin{abstract}
The article shows the key tendencies of the functioning of the institute of education in the network society. Specific features of dynamic changes in science and technology development and the transformation of the labor sphere are analyzed. The authors pay special attention to challenges and prospects of modern higher education system. It is shown the importance of possibilities of adapting existing educational system to new requirements of labor market while maintaining and reproduction of the classical values of higher education.
\end{abstract}

Keywords-education; network society; higher education; labor market; the Fourth Industrial Revolution

\section{INTRODUCTION}

Scientific and technological progress moves ahead rapidly and makes us think about how fast and how radically the social reality will change. The Third Industrial Revolution of the last third of the 20th century led to changes in labor market which became more flexible, and made the educational sphere face the necessity to address the new requirements to graduates from employers. Experts of the World Economic Forum held in Davos in January 2016 proposed to discuss the Fourth Industrial Revolution and its possible consequences. Statements that the world is at the threshold of the Fourth Industrial Revolution [1] and forecasts about inevitable quality changes of capitalist economic models raise serious discussions concerning the further development of the society.

Innovations of the Third Industrial Revolution allowed creation and introduction of digital and information technologies, whereas scientific achievements allowed interaction within physical, biological and digital environment [1]. New digital epoch which replaces the industrial epoch, so-called "second epoch of machines", is characterized by the presence of three fundamental characteristics: "exponential development, digitalization of information and recombining as a key source of the innovation-driven growth" [2]. As a result, understanding of work and leisure changes, and day-to-day communication and self-expression changes as well. Changes also refer to the political system, health and education spheres.

Researches define the modern society as "digital" [3, 4, 5]. Such society faces weaker market mechanisms, breaking former interconnections between the salary, labor and profit instead of strengthening the key principles of capitalism by creating new information technologies [6]. Results of the scientific and technological progress allowed stipulating information economy, cognitive or information capitalism, third-type capitalism and even the nearest post-capitalist future $[6,7,8]$.

The modern economic activities are made of production, reproduction and exchange of information. That is why the labor market sets high requirements for special knowledge and higher education. With this, the modern production assumes mandatory ability of an employee to "create himself" by obtaining skills that are taught nowhere but are of growing demand among the employers. This regards, first of all, skills of team work under high risk and permanent uncertainty, ability to solve non-standard tasks. Due to the rampant development of science, the technical knowledge is depreciating very fast. Consequently, resources of secondary and higher education allow only getting the basic knowledge, which every individual has to increase all his/her career long.

\section{UNIVERSITIES IN THE GLOBAL EDUCATION}

In the modern world the educational establishments compete as much as corporations. One of any educational establishment's success factors is a position it has in the international ratings. It serves as a guide for many applicants in their efforts to understand which universities will ensure competitive advantages in the labor market. Flexibility, ability to adapt, quick response to changes are the necessary qualities to become successful in the capitalist system, and this idea is understood both by companies and universities. They do their best to adapt to the quickly changing external circumstances. 
Classic universities still occupy leading positions in the international ratings, while the cities where they are located are very popular among youngsters and other groups. Oxford, Cambridge, Bologna, Ghent, Heidelberg, Munster, Marburg, Freiburg, Tartu, Krakow and others are typical university cities. Their functioning depends on educational establishments located there. Such universities become the core centers of social and cultural development of the city, or even of the whole region. Concentration of highly educated citizens reduces the risk of problematic social environment, which raises the city attractiveness and creates advantageous conditions for education. The reason why students choose the universities in the Southern Europe (Spain, Italy, Portugal) can be explained by the attractiveness of the countries themselves and certain cities from touristic point of view (history, culture, sights, climate, etc.). Young people often leave metropolitan cities to study in the campuses where everything is focused on needs of students and educators. Internationalization trends maximally involve the sphere of the higher education where it develops in various forms cross-border education. Modern education is pretty much international, and such feature becomes more and more evident with the growing globalization.

Universities of large cities, such as Paris, London, Berlin, Moscow are also popular among the applicants. Certain universities are still located in the metropolitan cities as far as the educational industry is concentrated in the large cities, especially global ones, showing high demand in intellectual services. In the beginning of this century the leading world cities become multi-function centers playing several roles simultaneously: centers of political power, international trade, hence, the centers of banking, insurance and adjacent financial services; centers of the modern professional activities in all spheres (medicine, education, science, etc.); centers of collection and distribution of information, centers of demonstrative consumption of luxury goods for the minority and mass-produced goods for the majority; centers of art, culture and entertainment, as well as auxiliary activities providing services for them [9]. Large corporations can produce goods in any place, but they also need to have access to the whole complex of new specialized services which are actually provided in global cities. Global cities are post-industrial production areas, a kind of borderline spaces which allow global corporations to integrate into the national economy [10]. Location of educational establishments in the global cities is a part of strategy, as far as the cities have demand for the whole range of services offered by the universities (educational as well as research, consulting, etc.).

Education in the universities of the global cities allows combining education and part-time work. Students working during their education period want to have competitive advantages upon their entry to the labor market after graduation. Economic factor of the education becomes more and more significant, and this is important not only for students. Several researchers note that in recent years education has been developing mostly as a service sector resulting in its "economization" or "marketization" [11]. Educational sector and its key components, including universities, are more and more often regarded as a factor of production. It is analyzed on the basis of economic approach with such notions as "education services", "economic efficiency", "human capital". Correspondingly, the universities do their best to become the suppliers of resources, first of all, for global markets.

\section{TRANSFORMATION OF EDUCATION In Digital AGE}

New digital age demonstrates two fundamental qualities. First, increase of demand for talented highly professional specialists and reduced demand for routine works where machines replace humans step by step. Second, the share of expenses for salaries in the structure of income is reducing and the share of the owner's profit is growing. These circumstances characterizing the "second epoch of machines" become the reason of the growing inequality between the leaders of the industry and all others. We face the situation where machines replace human labor much faster than before. At the same time, they increase the capital reproducing themselves. It means that the future belongs to those ready to create and introduce innovative products and services. Owners of the traditional capital and those providing cheap labor will be forced out by automation.

The basis of the modern enterprise is a complex of networks supporting instant conversion of signals into market products with help of data processing. This assumes development of a new system of labor relations, including individualization of the employment schemes. Demands of the new labor market testify that the existing educational systems are obsolete. Earlier a worker had to strictly follow the regulations and instructions, remember information, but nowadays such tasks can be implemented by machines. Researchers of the labor market forecast that in 20 years from 10 to $50 \%$ (according to various assessments) of the existing professions will disappear, and one third of the new ones will require skills unknown today [12].

Individualization of labor sets new requirements to employees which will be highly educated and initiative, able to freely "reprogram themselves in alignment with the constantly changing objectives of the developing business environment". "Self-programming labor" requires a new type of education where the fund of knowledge and information will increase and change all lifelong. Obtaining an intellectual ability to study during the whole life is rather important. This includes finding information stored in a digital form, processing it and using to produce knowledge corresponding to certain purpose [13]. Along with the necessity to select, filter or search additional information in the huge amounts, netocrats [5] refer to knowledge and skills of other individuals with possibilities offered by the ICT. Knowledge and experience of an individual social network participants extend their intellectual abilities and allow finding new solutions in the process of labor activities. Nowadays, search of opportunities to transform the educational system is one of the key issues. In the network society, a worker requires an ability to obtain new professional competencies or to improve the existing ones in accordance with the requirements of the short-term projects. Project work, typical for the network enterprise, assumes 
permanent addition of new knowledge due to absence of standard rules and procedures.

Education is the most important basis of development of the human potential. Access to the education for the wide layers of citizens defines opportunities of social development. However, we have to understand that the possibility to get a higher education by all who desire it leads to its mass nature and its devaluation. Certain researchers note that the mass nature of education in Russia has led to a free access to the third-rate universities and limited access to elite ones [14]. Today, higher education in Russia has actually become a kind of attribute of a life style or, else, a product everyone wants to obtain [11]. Similar situation is seen not only in Russia, but in different countries as well.

According to Fukuyama, elite schools and universities offer the highest quality of educational services ever, while the level of teaching in all others reduces simultaneously [15]. Several years ago online courses were pinned with greatest hopes. They were intended to become the beginning of a new epoch which would open the doors into the world of elite education to all at minimum charge or free-of-charge at all. But these hopes turned null.

Researches show that, first, online courses cannot attract significant number of trainees from disadvantaged population, and, second, results of studies are much worse than the results of those who attend a full-time course. This is hardly a surprise because only about $4 \%$ of the subscribers complete the whole course [16]. Nowadays the online courses are mostly popular among those who already have a higher education and high motivation towards obtaining additional education. However, their extension leads to the reduced number of teachers and the total salary of teachers of traditional courses. Ford says that from 1985 till 2013 the cost of higher education rose by $538 \%$, however, expenses spent to the education itself did not grow significantly but costs of administration and material part of the process increased massively [16]. It is not the" quality of education", that grows. It is the cost of its resources.

\section{CONCLUSION}

Hence, we can say that traditional values of the higher education are being forced out. Classic universities, however, try to reduce the negative effects of marketization. Hopefully, they can find a reasonable balance between the market requirements and the classic values of the higher education, and education system can focus on quality, but not the quantitative factors. But today "the quality of education" still means the position of the educational establishment held in the university ratings. However, the paradox here is that certain ratings focus on the results of the scientific and research activities (number of Nobel prize winners, highly cited researchers, etc.) leaving the teaching (education) activities of the universities overshadowed.

Regardless of all the aforementioned, many researches are very optimistic about the future. For example, Rifkin speaks about the extended access rights, including assess to the education [8]. Fukuyama also believes in new alternatives in the nearest future and considers that the middle class rapidly losing achievements of the 20th century will offer an alternative path of development [15].

Digital world of the future assumes development of the team skills and creativity. Need of innovative thinking, developing of creativity and entrepreneurial spirit become the key principles for development of new educational programs at all stages of education. Knowledge and technology made a modern individual "become inevitably inventive". According to Serres, this circumstance becomes encouraging for a young generation, as far as from now on labor becomes more creative rather than monotonous as it is now [17].

\section{REFERENCES}

[1] Schwab K. The Fourth Industrial Revolution. New York: Crown Business, 2017

[2] Brynjolfsson E., McAfee A. The second machine age: work, progress, and prosperity in a time of brilliant technologies. New York: W. W. Norton \& Company, 2014.

[3] Castells $M$. The Rise of the Network Society: The Information Age, Society and Culture. Vol. 1. Singapore: Wiley-Blackwell, 2010.

[4] Van Dijk J. The Network Society. Social Aspects of New Media. 2nd ed. SAGE, 2006.

[5] Bard A., Söderqvist J. Netocracy - The New Power Elite and Life After Capitalism. London: Pearson FT Press, 2002.

[6] Mason P. PostCapitalism: A Guide to our Future. London: Allen Lane, 2015.

[7] Castells M. The Informational City: Economic Restructuring and Urban Development. Oxford - Cambridge: Blackwell, 2002.

[8] Rifkin J. The Zero Marginal Cost Society: The Internet of Things, the Collaborative Commons, and the Eclipse of Capitalism. New York: Palgrave Macmillan, 2014.

[9] Hall P. Christaller for a Global Age: Redrawing the Urban Hierarchy // GaWC Research Bulletin 59. October 2001. URL: http://www.lboro.ac.uk/gawc/rb/rb59.html, accessed: 27.12.2016.

[10] Sassen S. The Global City: Enabling Economic Intermediation and Bearing Its Costs // City \& Community. Vol. 15. № 2. June 2016.

[11] Kostjukevich S.V. Higher Education: Some Modern World-wide Tendencies // Sociological Almanac. 2012. No. 3. P. 103-114. (In Russian).

[12] Realizing Human Potential in the Fourth Industrial Revolution An Agenda for Leaders to Shape the Future of Education, Gender and Work.

http://www3.weforum.org/docs/WEF_EGW_Whitepaper.pdf (accessed: 14.04.2017)

[13] Castells M. The Internet Galaxy: Reflections on the Internet, Business and Society. New York: Oxford University Press, 2002.

[14] Hossler D. A Policy Analysis of the Status of Access and Equity in Russia // Paper presented to the 29th ANNUAL EAIR FORUM 26 to 29 August 2007 ed. by D. Hossler, O. Shonia, R. Winkle-Wagner. Innsbruck, 2007.

[15] Fukuyama F. The Future of History. Can Liberal Democracy Survive the Decline of the Middle Class? // Foreign Affairs. 2012. Vol. 91. N 1. URL: https://www.foreignaffairs.com/articles/2012-0101/future-history (accessed date: 14.04.2017).

[16] Ford M. Rise of the Robots: Technology and the Threat of a Jobless Future. New York: Basic Books, 2015.

[17] Serres M. Petite Poucette. Paris: Éditions le Pommier, 2012. 